\title{
Evaluation of Effectiveness between Two Different Facilities for Drinking Water Having Different Water Sources for Removal of Free-Living Amoeba in Qalyubia Governorate, Egypt
}

Lamiaa A. Shawkey*1, Faten A. Elfeky², Basma M. Abou-Elnour' ${ }^{2}$ Eman S. El-Wakil ${ }^{3}$

Reference Laboratory for Drinking Water ${ }^{1}$, Holding Company of Water and Waste Water, Shopra Elkhiema,

Qalyubia, Department of Zoology², Faculty of Science for Girls, Al-Azhar University, Cairo,

Department of Parasitology ${ }^{3}$, Theodor Bilharz Research Institute, Warrak El-Hadar, Imbaba, Giza, Egypt

*Corresponding author: Lamiaa A. Shawkey, Email: lamyaashwkey@yahoo.com

\begin{abstract}
Background: Conventional drinking water treatment plants (CDWTPs) and Ground water (GWTP) are the main 2 types of drinking water treatment using freshwater as a source for drinking water in Egypt. Objective: The Egyptian standards for drinking water denied the presence of any type of living protozoa in drinking water produced for human use.

Martials and methods: 48 water bodies were selected from Benha and Kaha districts in Qalyubia Governorate, Egypt. Mean turbidity, $\mathrm{pH}$, conductivity, temperature, ammonia, nitrite, iron, manganese, magnesium and residual chlorine were recorded in each water body from two sites. Centrifuged samples were cultured on non-nutrient agar plates with Escherichia coli. Positive sample isolates were subjected to DNA extraction and polymerase chain reaction using genus and species-specific primers targeting the internal transcribed spacer region (ITS) and Mp2CL5 gene. Results: The prevalence of Naegleria species, N. fowleri and Acanthamoeba in the study area were $54.1 \%$ and $0 \%$ ( N. fowleri and Acanthamoeba) of all sample examined. The removal of free-living amoebae from drinking water, it was shown that conventional DWTP (Benha) could get rid of 91\% of FLAs present in the raw untreated water, while ground DWTP removed only $55.6 \%$ of these organisms. Conclusions: The conventional drinking water treatment system for surface water was better than that of only chlorine disinfection for ground water in removing free-living amoeba (FLAs). In general, the persistence of FLAs in drinking tap water unfortunately exerts public health hazards.
\end{abstract}

Keywords: Amoebae, Microscopy, PCR, Drinking water treatment plant, Groundwater.

\section{INTRODUCTION}

"Water is life"; actually, water is the most plentiful compound on Earth and is vital natural resource for human health and essential to life. It is most important that water that people drink and use for other purposes must be clean water. The presence of microbial pathogens in source waters, drinking water and recreational water bodies is a global problem. Microbial contamination of drinking water contributes to disease outbreaks and background rates of disease in developed and developing countries worldwide ${ }^{(\mathbf{1})}$. Control of waterborne disease is an important element of public health policy and an objective of water suppliers. Waterborne diseases caused by the consumption of contaminated water can affect a large number of people in a short time ${ }^{(2)}$.

According to the World Health Organization (WHO), two million people die each year because of such illnesses, the majority of whom are children under the age of five. Furthermore, roughly 663 million people still do not have access to safe drinking water ${ }^{(3)}$. Free-living amoeba, which include the genera Acanthamoeba, Naegleria, Vahlkampfia and Vermamoeba/Hartmannella, are found all over the world. Some FLA species are potentially harmful to humans and flourish in a variety of environments, including freshwater and marine environments ${ }^{(4)}$. The global distribution of free-living amoeba varies from $23 \%$ to $89 \%$, depending on the geographic location ${ }^{(5)}$.

Several studies have identified the prevalence of living amoeba in Asia, including Thailand, China, and India ${ }^{(6)}$. The Acanthamoeba spp. incriminated in human infections can cause rare, but severe infections. They cause amoebic keratitis, granulomatous amoebic encephalitis, and disseminated granulomatous amoebic diseases (e.g., skin, sinus, and pulmonary infections) ${ }^{(7)}$. The genus Naegleria was originally grouped with the Amoebozoa because of having an amoeboid stage. However, based on molecular phylogenetics, it is currently classed as part of the Excavata ${ }^{(8)}$.

Despite the fact that there are over thirty Naegleria spp, only $N$. fowleri can infect humans ${ }^{(9)}$. This species is most often found in warm freshwater and soil environments. It infects individuals when contaminated water containing $N$. fowleri enters the body by the nose and then migrates to the brain, where it causes primary amoebic meningoencephalitis (PAM), which is generally deadly in healthy people ${ }^{(\mathbf{1 0})}$. The epidemiology studies on free-living pathogenic amoebae from both fresh and ground water have been conducted all over the world but their spreading in the environment in Egypt is still poorly understood. Therefore, the aim of the present study was to assess the prevalence of potentially pathogenic 
free-living amoebae for one year from two different drinking water treatment plant, conventional DWTP and Ground water DWTP. Besides, to compare between two different drinking water treatment facilities (CDWTP and GWU) for the removal of potentially pathogenic FLAs in Qalyubia Governorate, Egypt using morphological and molecular methods of detection.

\section{MATERIALS AND METHODS}

Sampling sites: Water samples were collected from two different drinking water treatment facilities (a conventional drinking water treatment plant and a ground water unit). Water samples were collected from 2 different drinking water treatment plants namely Benha and Kaha DWTP, located in Qalyubia Governorate, Egypt. Two sampling sites in Benha DWTP were examined representing raw (inlet) water and finished (outlet) water. Another two sampling sites in Kaha untreated ground water (inlet), chlorinated ground water (outlet) (Figure 1). Collected water samples were transported in icebox at $4-8^{\circ} \mathrm{C}$ to the laboratory (Reference lab for drinking water) at the same day of collection $^{(11)}$.

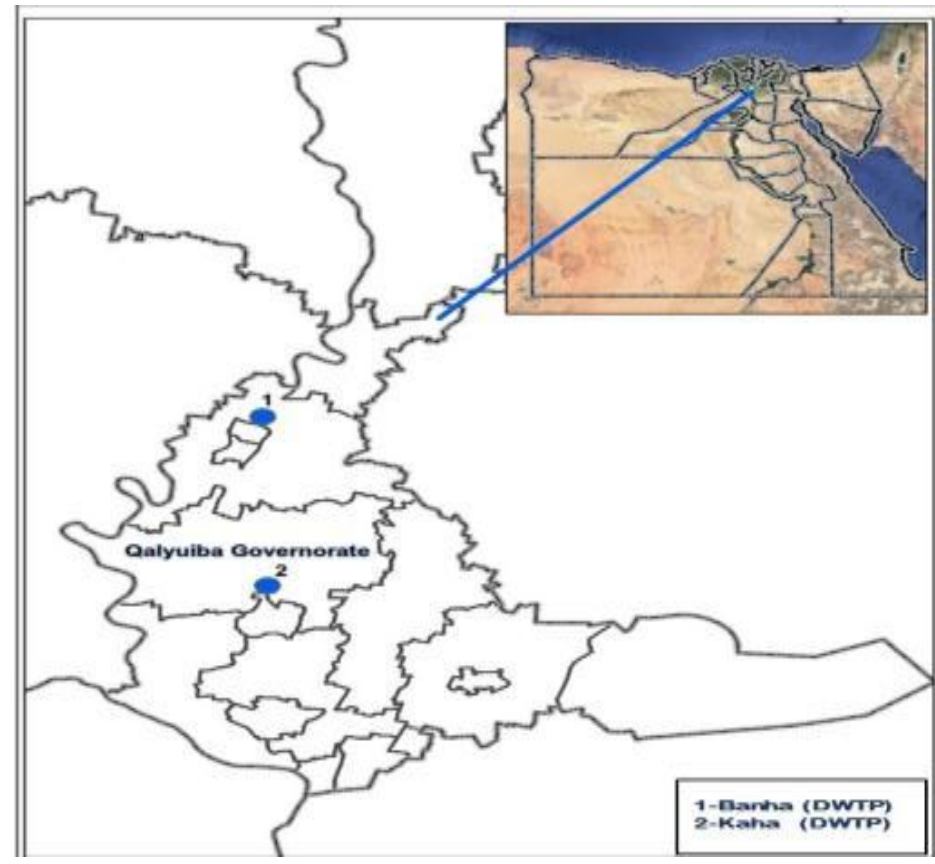

Fig. (1): Diagrammatic map for locations of water samples in Qalyubia Governorate.

Water quality: Physico-chemical and biological parameters were carried out according to Standard method for the examination of water and wastewater ${ }^{\mathbf{( 1 2})}$.

Physico-chemical characters: Physical and chemical parameters were measured in situ at each of the processing site prior to the collection of water samples. The physical parameters such as temperature and $\mathrm{pH}$ was measured by $\mathrm{HACH}$ sension 3, conductivity was measured by $\mathrm{HACH}$ sension 7 , and turbidity was measured using turbidity meter (HACH $2100 \mathrm{~N}$ Turbidimeter, Loveland, CO, USA) and chemical parameters such as ammonia, residual chlorine, nitrite, iron, manganese, and magnesium were measured using colorimeter (UV-1800 SHIMADZU spectrophotometer, Japan) in the laboratory. The parameters were then recorded as mean values at each sampling site were carried out according to APHA ${ }^{(12)}$ (Figures 2, 3, 4, 5, and $6)$.

\section{Statistical analysis}

The collected data were coded, processed and analyzed using the SPSS (Statistical Package for Social Sciences) version 22 for Windows ${ }^{\circledR}$ (IBM SPSS Inc, Chicago, IL, USA). The recorded Mean turbidity, pH, conductivity, temperature, ammonia, nitrite, iron, manganese, magnesium and residual chlorine mean of each sample were utilized for statistical analysis. Microscopic culture for free-living amoeba and PCR positive samples in each sample site were analyzed.

\section{Biological parameters:}

Concentration, culturing and sub culturing of FLAs: Water samples (one liter from each sampling site) were separately collected in sterile polypropylene containers labeled with the sampling site and date of collection and then transferred within 3 hours to the laboratory for subsequent filtration. The collection bottles were adequately shaken and water samples were then filtered using $0.45 \mu \mathrm{m}$ nitrocellulose membrane $(47 \mathrm{~mm}$ in diameter) using stainless steel vacuum filter holder (Sartorius), non-nutrient agar (NNA) was freshly prepared and poured into sterile plates that were refrigerated till used according to Ozcelik et al. ${ }^{(13)}$. In a biosafety cabinet using sterile wire loop, a colony of previously cultured Escherichia coli (E. coli) was dissolved in one $\mathrm{ml}$ sterile Page's Amoeba Saline (PAS) (120 mg NaCl, $136 \mathrm{mg} \mathrm{KH2PO4,} 142 \mathrm{mg} \mathrm{Na}$ HPO4, $4 \mathrm{mg} \mathrm{CaCl} 2$. 2H2O, $4 \mathrm{mg} \mathrm{MgSO} 4.7 \mathrm{H} 2 \mathrm{O}$ and $1 \mathrm{~L}$ distilled water). Three to four drops of $E$. coli-suspension were distributed evenly by sterile Pasteur pipette onto the surface of each NNA plate. The filter paper of each sample was subsequently inverted and placed face down on the culture plate and left at room temperature for $0.5-1$ hour during which the amoebae settled and adhered to the E. coli lawn. The plate was sealed by parafilm and incubated at $37^{\circ} \mathrm{C}$ base downwards (to evaporate any residual fluid) ${ }^{(\mathbf{1 4})}$.

\section{Morphological Identification of FLA:}

On the third day of the incubation, the filter paper was removed by sterile forceps and the culture plates were monitored daily by microscopic examination at $40 \mathrm{X}$ to identify Naeglaria cysts and trophozoites. The plates were considered negative after 14 days of incubation and 
were discarded. Flagellation test was done for positive culture samples by incubating the amoebae in a test tube containing $2 \mathrm{ml}$ distilled water for one to two hours to exclude the presence of any free-swimming flagellated forms ${ }^{(15)}$. For sub-culturing, PAS-containing trophozoites or cysts were further transferred into a new NNA-E. coli culture plate in the same way described above and the plates were then checked for amoebae growth ${ }^{(16)}$. To collect amoebae from the positive subculture plates, scraping of the plate surface was done using a sterile scalpel after adding 4-5 $\mathrm{ml}$ of PAS. Trophozoites and cysts along with the PAS were centrifuged for $5 \mathrm{~min}$ at $4000 \mathrm{rpm}$ in $10-\mathrm{ml}$ falcon tube to obtain sufficient sediment of amoebae. This step was repeated three times in order to remove additional agar and to isolate the highest amount of the amoeba ${ }^{(13)}$. The sediment was stored at $-20^{\circ} \mathrm{C}$ in sterile Eppendorf for subsequent DNA extraction, molecular confirmation by conventional PCR techniques using genus specific primers and further sequencing.

Molecular characterization of the isolated FLA: Morphological identification showed preserved putative isolates of Acanthamoeba, Naegleria and Naegleria fowleri that were subjected to DNA extraction and amplified using genus-specific primers (Table 1). DNA extraction was done by using $1.5 \mathrm{~mL}$ tube containing 1 $\mathrm{mL}$ of saline buffer, centrifuged at $6000 \mathrm{rpm}$ for $10 \mathrm{~min}$, and then the pellet was re-suspended in $100 \mathrm{~mL}$ of saline buffer and used for genomic-DNA extraction (by G$\operatorname{spin}^{\mathrm{TM}}$ Total DNA Extraction Mini Kit) following the manufacturer's specifications. PCR reaction conditions and mixtures were performed according to Pelandakis $\boldsymbol{e t}$ al. ${ }^{(18)}$. Gel electrophoresis of PCR products was done using $1.5 \%$ agarose gel. The gel was stained with ethidium bromide to visualize PCR products under UV light ${ }^{(19)}$.

Table (1): Primers used in this study.

\begin{tabular}{|c|c|c|}
\hline Organism & Primer sequence & Reference \\
\hline $\begin{array}{l}\text { Acantham } \\
\text { oeba } \\
\text { Spp. }\end{array}$ & $\begin{array}{l}\text { F JDP15`- } \\
\text { GGCCCAGATCGTTTACCGTGA } \\
\text { A-3` } \\
\text { R JDP2 5`- } \\
\text { TCTCACAAGCTGCTAGGGAGT } \\
\text { CA3` }\end{array}$ & $\underset{(20)}{\text { Kilic et al. }}$ \\
\hline $\begin{array}{l}\text { Naegleria } \\
\text { Spp. }\end{array}$ & $\begin{array}{l}\text { F5`GAACCTGCGTAGGGATCAT } \\
\text { TT- }{ }^{`} \\
\text { R5`- } \\
\text { GAACCTGCGTAGGGATCATTT } \\
-3^{`}\end{array}$ & $\begin{array}{l}\text { Pelandakis } \\
\text { et al. }{ }^{(18)}\end{array}$ \\
\hline $\begin{array}{l}\text { Naegleria } \\
\text { fowleri. }\end{array}$ & $\begin{array}{l}\text { F:5`- } \\
\text { GTGAAAACCTTTTTTCCATTT } \\
\text { ACA-3` R:5`- } \\
\text { GAACCTGCGTAGGGATCATTT } \\
-3^{`}\end{array}$ & $\begin{array}{l}\text { Pelandakis } \\
\text { et al. }{ }^{(18)}\end{array}$ \\
\hline
\end{tabular}

\section{RESULTS}

\section{Physical and chemical parameters for conventional DWTP.}

The physical and chemical parameters are summarized in (Figures 2, $3 \& \mathbf{4}$ ). The parameters (overall mean for plant Benha DWTP for raw and treated water respectively) included temperature $\left(20.6,20.94^{\circ} \mathrm{C}\right)$, conductivity (overall mean 412.38 and $421.04 \mathrm{~ms} / \mathrm{cm}$ ), $\mathrm{pH}$ (overall mean: 7.8 and 7.2) and turbidity (overall mean: 7.78 and 0.29 NTU (Nephelometric Turbidity Unit)). Meanwhile, chemical tests including ammonia (overall mean: 0.07 and $0.02 \mathrm{mg} / \mathrm{L}$ ), chlorine (overall mean: 0 and $2.06 \mathrm{mg} / \mathrm{L}$ ), nitrite (overall mean: 0.04 and $0.01 \mathrm{mg} / \mathrm{L}$ ), magnesium (overall mean: 0.29 and 0.11 $\mathrm{mg} / \mathrm{L}$ ), iron (overall mean: 0.29 and $0.11 \mathrm{mg} / \mathrm{L}$ ) and manganese (overall mean: 0 and $0 \mathrm{mg} / \mathrm{L}$ ) were also measured and analyzed.

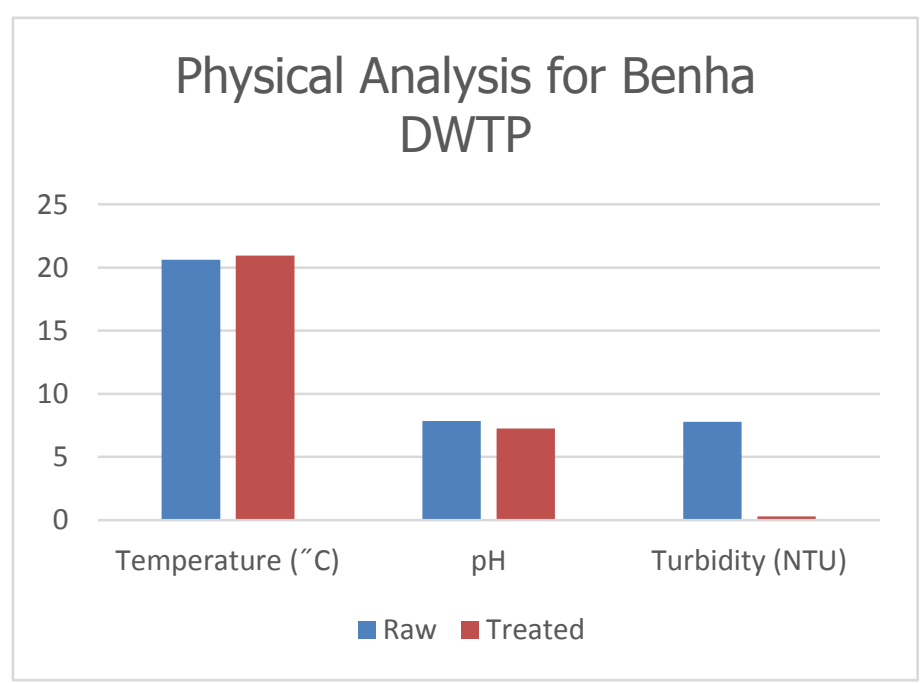

Fig. (2): Mean values of temperature, $\mathrm{pH}$,turbidity from Benha DWTP.

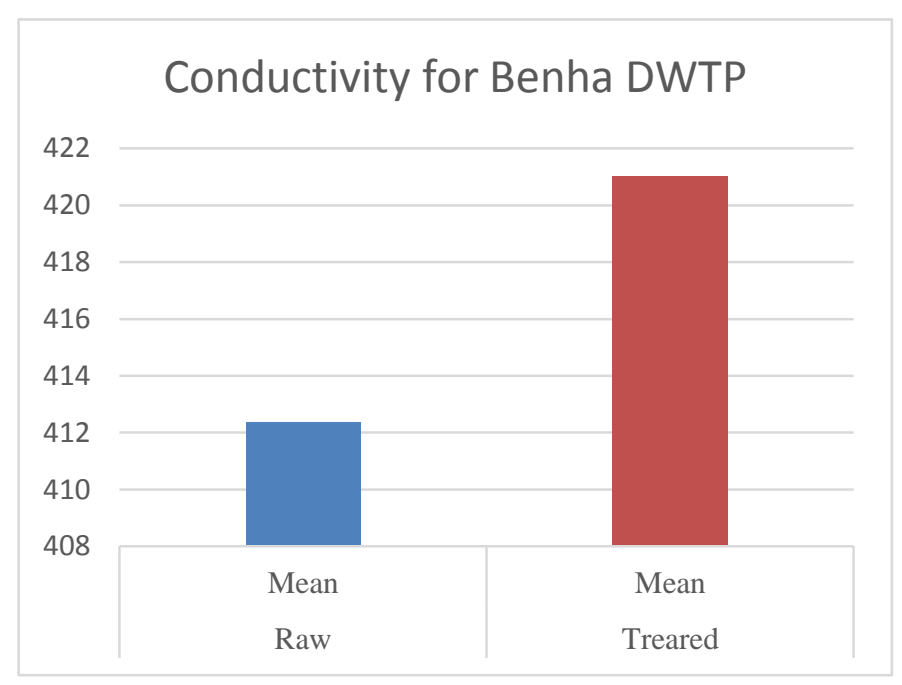

Fig. (3): Mean values of conductivity from Benha DWTP. 


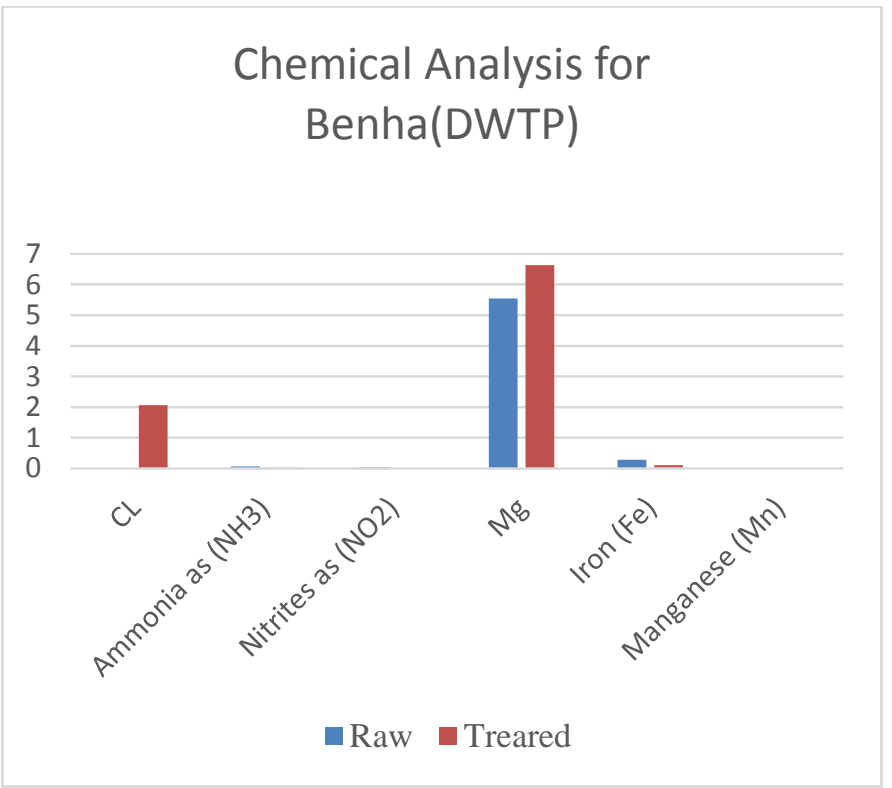

Fig. (4): Mean values of CL, Ammonia, Nitrites, Mg, Iron, Manganese from Benha DWTP.

Physical and chemical parameters for ground DWTP:

The physical and chemical parameters are summarized in (Figures 5, $6 \&$ \& $)$. The parameters (overall mean for plant Kaha DWTP for raw and treated water respectively) included temperature (24.13 \& $23.47^{\circ} \mathrm{C}$ ), conductivity (overall mean 1178 \& 819.42 $\mathrm{ms} / \mathrm{cm}$ ), $\mathrm{pH}$ (overall mean: $7.36 \& 7.35 \mathrm{PH}$ ) and turbidity (overall mean: $3.43 \& 2.07 \mathrm{NTU}$ (Nephelometric Turbidity Unit)). Meanwhile, chemical tests including ammonia (overall mean: $0.16 \& 0 \mathrm{mg} / \mathrm{L}$ ), chlorine (overall mean: $0 \& 1.41 \mathrm{mg} / \mathrm{L}$ ), nitrite (overall mean: 0 \& $0 \mathrm{mg} / \mathrm{L}$ ), magnesium (overall mean: $0 \& 0.05 \mathrm{mg} / \mathrm{L}$ ), iron (overall mean: $0.41 \& 0.12 \mathrm{mg} / \mathrm{L}$ ) and manganese (overall mean: $0.17 \& 0.05 \mathrm{mg} / \mathrm{L}$ ) were also measured and analyzed.

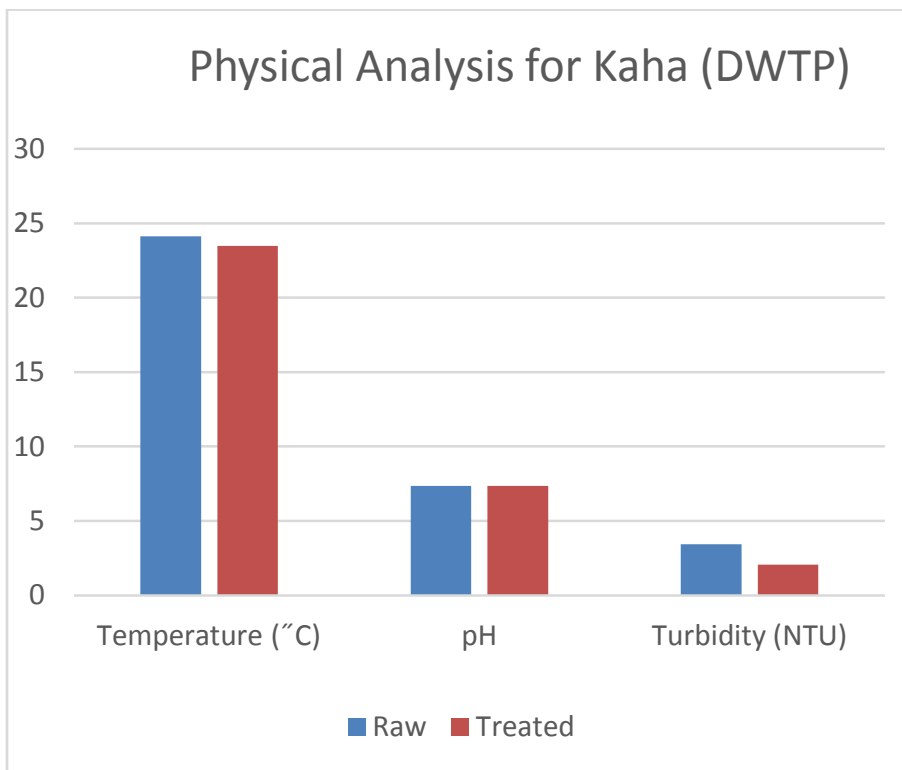

Fig. (5): Mean values of temperature, $\mathrm{pH}$ and turbidity from Kaha DWTP.

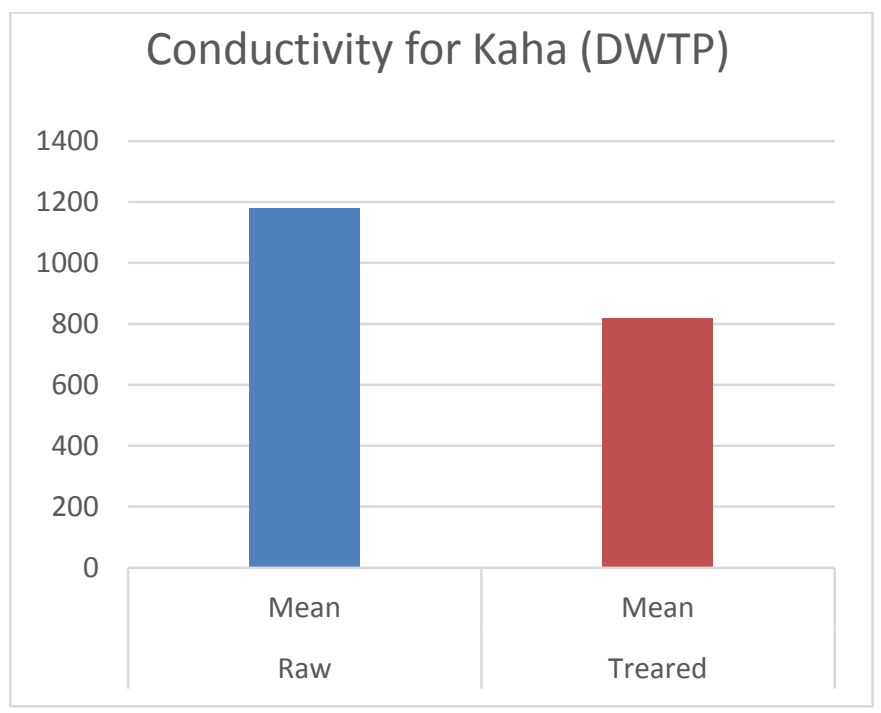

Fig. (6): Mean values of Conductivity from Kaha DWTP.

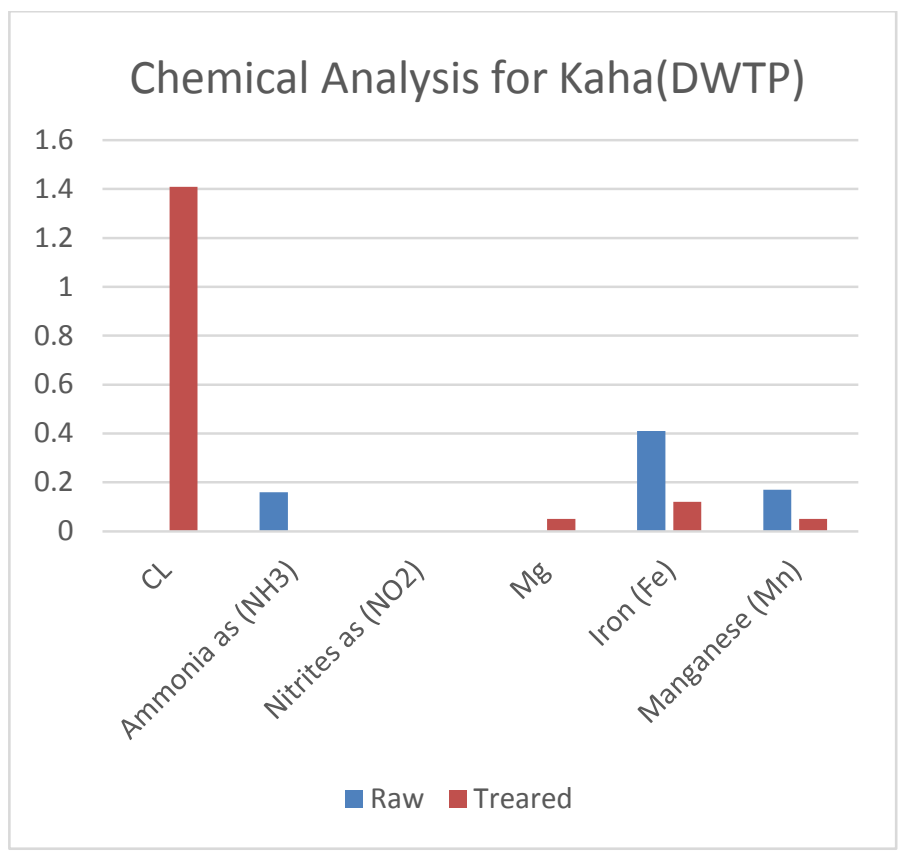

Fig. (7): Mean values of CL, Ammonia, Nitrites, Mg, Iron, Manganese from Kaha DWTP.

\section{Biological parameters:}

Pathogenic free-living amoebae were detected in $91.6 \%$ and $75 \%$ of raw water samples from the examined inlet (untreated) of conventional and ground drinking water treatment plants respectively. Consequently, FLAs were detected in $8.3 \%$ and $33.3 \%$ of treated (finished) water samples from conventional and ground DWTPs respectively (Table 2 ). 
Table (2): Total occurrence of potentially pathogenic FLAs in the examined DWTPs by culture and PCR.

\begin{tabular}{|c|c|c|c|c|c|c|c|c|}
\hline \multicolumn{5}{|l|}{ Benha DWTP } & \multicolumn{4}{|c|}{ Kaha DWTP } \\
\hline & \multicolumn{2}{|l|}{ Raw } & \multicolumn{2}{|l|}{ Finished } & \multicolumn{2}{|l|}{ Raw } & \multicolumn{2}{|c|}{ Finished } \\
\hline & Culture & PCR & Culture & PCR & Culture & PCR & Culture & PCR \\
\hline Examined samples & 12 & 12 & 12 & 12 & 12 & 12 & 12 & 12 \\
\hline Positive samples & 12 & 11 & 1 & 1 & 9 & 9 & 4 & 4 \\
\hline$\%$ & 100 & 91.6 & 8.3 & 8.3 & 75 & 75 & 33.3 & 33.3 \\
\hline
\end{tabular}

Concerning the removal of free-living amoebae from drinking water, it was shown that conventional DWTP (Benha) could get rid of $91 \%$ of FLAs present in the raw untreated water, while ground DWTP removed only $55.6 \%$ of these organisms (Table 3). In addition, the presence of free-living amoebae in the finished water (completely treated drinking water) was an indication that there were some defects in the application and performance of drinking water treatment steps (Fig. 8).

Table (3): Removal of pathogenic free-living amoebae in the examined DWTPs.

\begin{tabular}{|l|c|c|c|c|}
\hline \multicolumn{4}{|c|}{ Pathogenic free-living amoeba } & Kaha DWTP \\
\hline & Raw & Finished & Raw & Finished \\
\hline Positive samples & 11 & 1 & 9 & 4 \\
\hline Removed & & 10 & & 5 \\
\hline Removal \% & $91 \%$ & & $55.6 \%$ \\
\hline
\end{tabular}

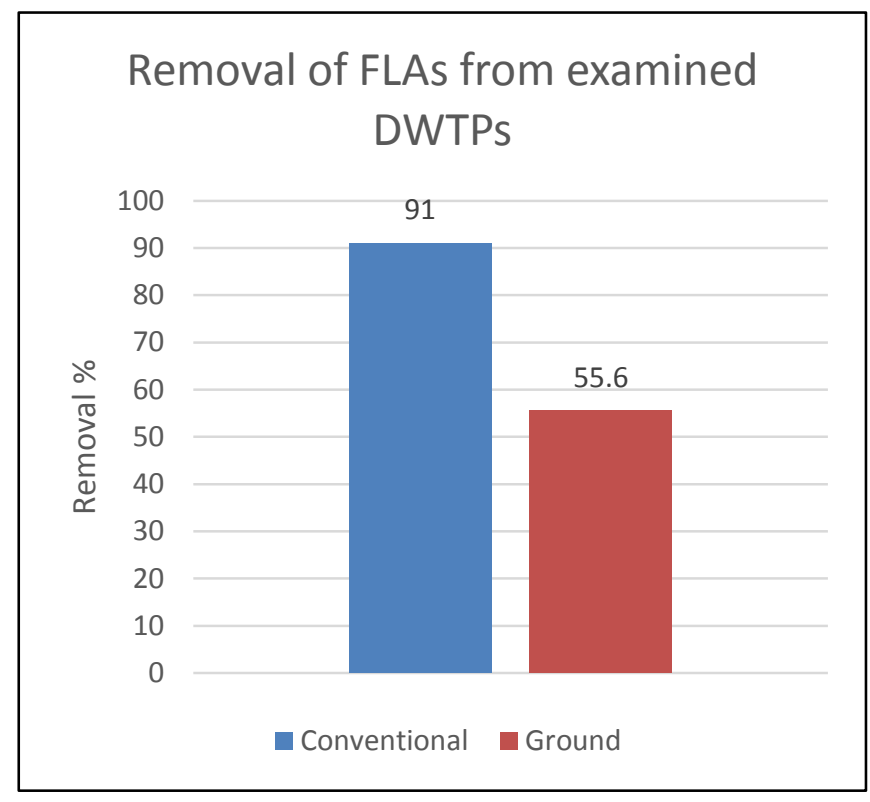

Fig. (8): Efficiency of DWTPs for FLA removal.

Significant negative correlations were observed between the presence of Free-living amoeba with residual chlorine $(\mathrm{r}=0.786, \mathrm{p}<0.01)$ in treated water (Kaha DWTP). Similarly, the occurrence of free-living amoeba showed significant correlations with conductivity $(\mathrm{ms} / \mathrm{cm})(\mathrm{r}=0.599, \mathrm{p}<0.05)$ in treated water (Kaha DWTP). No significant correlations were found between the occurrence of these protozoa and the conductivity $(\mathrm{ms} / \mathrm{cm})$ in treated water (Benha DWTP). Moreover, there was also significant negative correlation with ammonia ( $\mathrm{r}$
$=0.612, \mathrm{p}<0.05)$ in raw water (Benha DWTP). In addition, there was also no significant correlation with iron, manganese, nitrate, temperature, $\mathrm{pH}$ and turbidity for both (DWTP). The conventional drinking water treatment plant had a strong significant effect for removal of free-living amoebae $(\mathrm{P}-\mathrm{Value}=0.000)$ from the inlet raw water. In addition, the Ground drinking water treatment had a significant effect for removal of free-living amoebae $(\mathrm{P}$-value $=0.001)$. The conventional DWTP was more efficient than ground DWTP for removal of FLAs.

In comparison between inlets of the two examined drinking water treatment plants, the obtained data declared that the inlet of conventional DWTP was more contaminated with parasitic protozoa and pathogenic FLAs than that of ground DWTP. At the same time, statistical analysis revealed that there was no significant difference between the prevalence of FLAs in raw water collected from the inlets of both conventional DWTP and ground DWTP.

With respect to genera of FLAs isolated in the present work genera (Naegleria) was isolated morphologically from inlet of DWTP water samples $21 / 21(100 \%)$ and 5/5 (100\%) of Naegleria spp can persist treatment and escape to fully finished drinking water. None of genera Acanthamoeba and Naegleria fowleri were detected morphologically from inlet or finished water sample. Out of the 20 (95.2\%) microscopically Naegleria-like positive inlets samples, 5 $(100 \%)$ were PCR positive using Naegleria genus specific primer (Table 4). None of genera (Acanthamoeba, Naegleria fowleri) was amplified by species-specific primer (Fig. 9). 


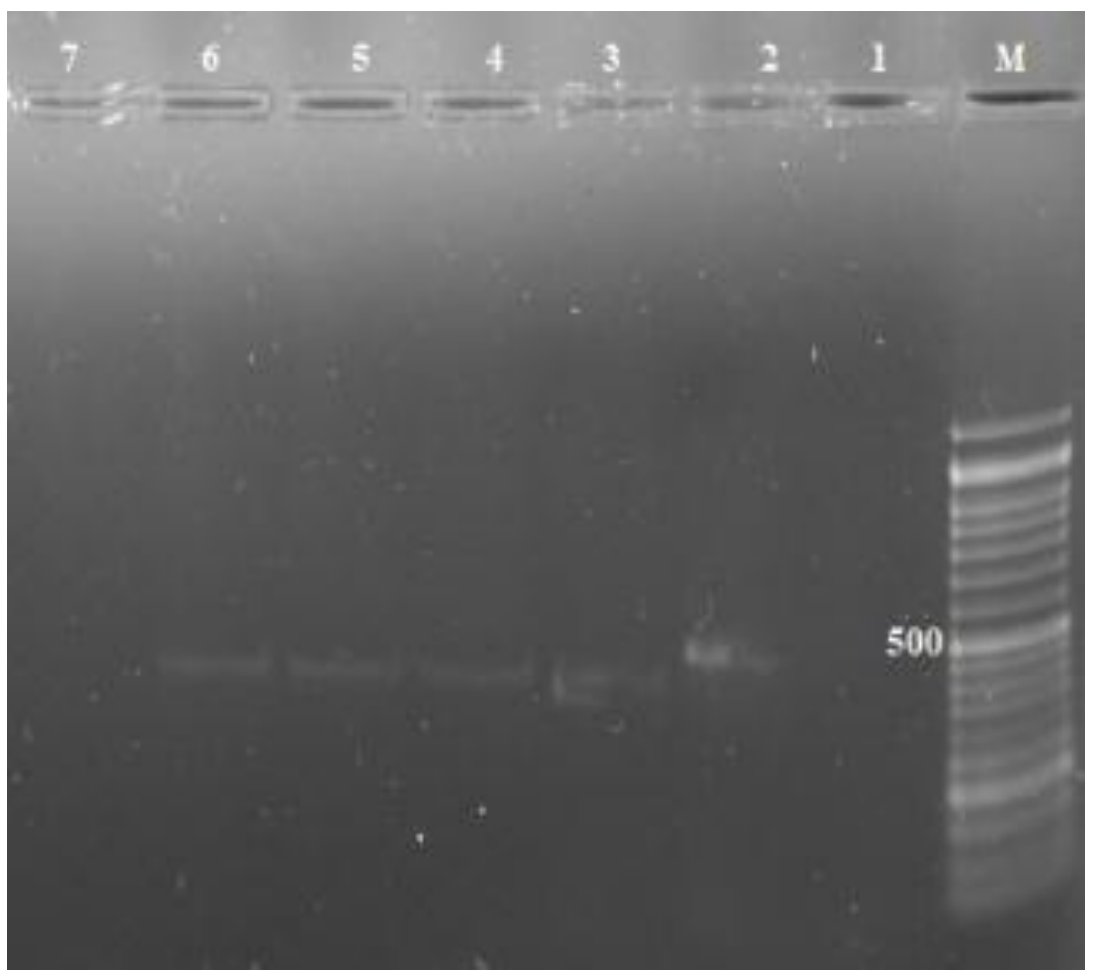

Fig. (9): PCR amplification of internal transcribed spacer (ITS) rDNA region. Lane M: DNA marker of 50 bp molecular weight. Lane 1: Negative sample. Lane 2, 3, 4, \& 5: Positive samples. Lane 6: Positive control. Lane, 7: Negative control.

Naegleria trophozoite showed uroid, lobopod, and multiple vacuoles in the cytoplasm; measures of 20 to $35 \mu \mathrm{m}$ in length with an average of $27.5 \mu \mathrm{m}$. At the anterior end, a wide hyaline lobopod was observed, and at the posterior end, a prominent villous uroid was observed. Cysts were round, smooth and of double wall with pores; they measured on average $15 \mu \mathrm{m}$ in diameter; the nucleus showed chromatin granules in the periphery, and a centric dense small nucleolus surrounded by a clear halo (Fig. 10).

Table (4): PCR positive samples for free-living amoeba in different sampling sites of examined DWTPs.

\begin{tabular}{|l|c|c|c|c|c|c|c|}
\hline \multirow{2}{*}{ Sampling sites } & \multirow{2}{*}{$\begin{array}{c}\text { Positive } \\
\text { amoeba } \\
\end{array}$} & \multicolumn{2}{c|}{$\begin{array}{c}\text { Acanthamoeba } \\
\text { (PCR) }\end{array}$} & \multicolumn{2}{c|}{$\begin{array}{c}\text { Naegleria spp. } \\
\text { (PCR) }\end{array}$} & \multicolumn{2}{c|}{ N. fowleri. (PCR) } \\
\cline { 3 - 8 } & Positive & \% & Positive & $\%$ & Positive & \% \\
\hline Inlets of DWTPs & 21 & 0 & 0 & 20 & 95.2 & 0 & 0 \\
\hline Finished water & 5 & 0 & 0 & 5 & 100 & 0 & 0 \\
\hline Total & 26 & 0 & 0 & 25 & 96.1 & 0 & 0 \\
\hline
\end{tabular}
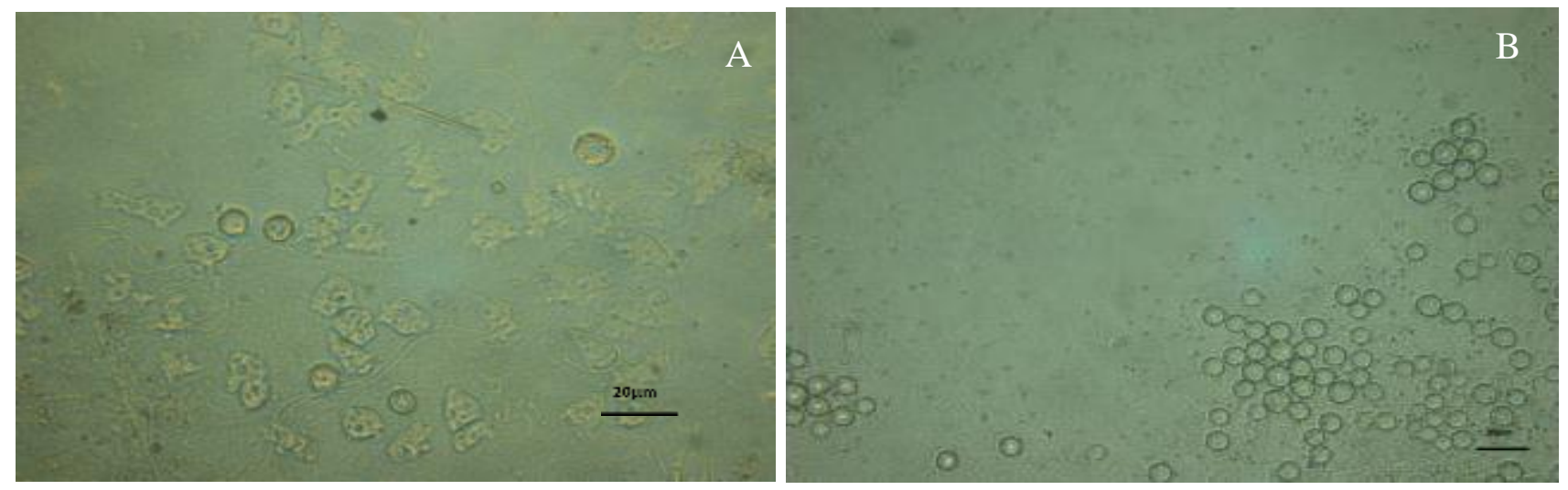

Figure (10): Fresh unstained Naegleria trophozoite (A) and cysts (B). 
https://ejhm.journals.ekb.eg/

\section{DISCUSSION}

Drinking water treatment-plant plays a key role in providing safe drinking water to consumers and the findings from this study will give us an insight on the water quality as well as processing sites that needs regular monitoring and intervention steps to be taken. Raw water is easily contaminated, thus, drinking water need to be processed in the treatment plant before being distributed. Coagulation and flocculation process is considered an essential component in a treatment plant to assist filtration process to function effectively, hence, able to remove microorganisms as well as other solid matters caused by soil erosion or decaying vegetation $^{(21)}$.

Investigation of physical and chemical parameters of 48 water samples demonstrated that almost all the parameters (turbidity, remaining chlorine, temperature, $\mathrm{pH}$, ammonia, nitrite, iron, manganese, magnesium and conductivity) were in normal range considering standards of APHA Organization. In addition, temperature of water resources contaminated with freeliving amoebas was studied, which showed that these amoebas could grow and be present at temperate temperature ranging between 12 and $25.9{ }^{\circ} \mathrm{C}$. These results are in agreement with Ghadar-ghadr et al. ${ }^{(22)}$.

The maximum occurrence of free-living amoebae in water samples obtained from raw surface water (inlet of Benha DWTP) was $91.6 \%$ in Benha DWTP, followed by $75 \%$ in Kaha DWTP in Qalyubia governorate in the current study. Other researchers in Egypt found FLAs in $75 \%$ of Nile water samples from Giza governorate and $91.7 \%$ of raw surface water in Fayuom governorate ${ }^{(23)}$. Other investigations in other countries, such as Bulgaria ${ }^{(24)}$ and Japan ${ }^{(14)}$, reported that FLAs were discovered in 94 percent and 68.7 percent of surface water, respectively. FLAs were isolated from surface source waters with a high frequency $(75-100 \%)$ in the United States ${ }^{(25)}$. Other studies in Egypt's Minofeya governorate found pathogenic free-living amoebae in all studied water samples from the entrance (raw surface water) of Quisna DWTP (ground water) ${ }^{(26)}$. Moreover, FLAs were detected in $85.7 \%$ of samples from well water in Italy ${ }^{(27)}$ and $44.4 \%$ of samples from well water in Iran (22). Free-living amoebae were detected in $41(85.4 \%)$ of 45 samples from various springs in Mexico (28). Topographic characteristics and the quality of raw water sources may influence the variation in FLA detection rates in different countries and locations ${ }^{(\mathbf{2 9})}$.

The current study found a significant difference in the presence of pathogenic FLAs in generated drinking water from the two DWTPs studied. The pathogenic FLA contamination of conventional DWTP finished water was lower than that of ground water DWTP finished water. Al-Herrawy et al. ${ }^{(23)}$ documented results of completed water in Giza governorate for conventional DWTP (16.7\%) and (29.2\%) in Minofeya governorate for ground DWTP in Egypt ${ }^{(9)}$.

In the current study, the removal effectiveness of free-living amoebae throughout the drinking water treatment process was found to be greatest in Benha DWTP (91\%), followed by Kaha DWTP (55.6\%). Other Egyptian researchers discovered that treatment techniques used at various phases of drinking water treatment manufacturing in Giza governorate were able to eliminate $76.2 \%$ of FLAs found in the input water (23). Although all intake samples from Giza governorate DWTP included FLAs, this record was lower than that of the current investigation. The increased elimination of FLAs from Benha DWTP, in our opinion, indicated that treatment processes were conducted more efficiently than in Giza governorate DWTPs. FLAs were also found in ground water in Egypt, with the highest percentage removal effectiveness $(70.8 \%)$ in Quisna DWTP in Minofeya governorate ${ }^{(9)}$.

The presence of FLAs in untreated ground water was unexpected as the ground water is more conserved and considered inside a closed earthy system than raw surface water, which is an open system directly exposed to different environmental contaminants. Moreover, the treatment process in Benha DWTP was considered a complete conventional drinking water treatment system in which each treatment step (coarse sieves, coagulation, sand filtration and final disinfection) removes part of raw water contaminants (including FLAs). So, most of the debris including FLAs are removed by these formerly mentioned steps (30). In the same time, the final disinfection step (3-5 ppm chlorine) kills viruses, bacteria, algae and only some vegetative forms of protozoa including FLAs, but cyst forms of FLAs are resistant to this disinfection dose. On the other side, no treatment steps occurred in Kaha DWTP, except the usual disinfection dose of chlorine that does not exceed $7 \mathrm{ppm}$ even in hot seasons. Other workers agreed with us in that the usual chlorine dose used for disinfection of the produced drinking water is ineffective of killing protozoa, especially cyst stages of FLAs ${ }^{(31)}$.

In the present work, the prevalence of amoebae belonging to genus Acanthamoeba was not detected in the examined water samples neither by morphological criteria nor by PCR techniques. To the best of our knowledge, amoebae of genus Acanthamoeba was not isolated from the Egyptian aquatic environment in this study. Although, the presence of this organism in a higher percentage $(100 \%)$ in almost all the examined water type in fayoum governorate, Egypt ${ }^{(32)}$. This might be due to high cultivation temperature $\left(37^{\circ} \mathrm{C}\right)$ or by geographic distribution. 
By PCR, $95.2 \%$ of the morphologically identifiable Naegleria strains isolated from raw water samples were shown to be linked to the genus Naegleria in the current investigation. Other researchers in Egypt discovered that in microscopically positive isolates from Nile water, the recovery rate of Naegleria-positive PCR samples reached $88.9 \%$ (almost identical to the current study) ${ }^{(33)}$. In 26 culturally positive Nile water samples for Naegleria, other Egyptian researchers found a slightly lower percentage of Naegleria ( $82.9 \%$ and $80 \%$ ) by PCR (31). Members of the genus Naegleria were found in 80 percent of water samples taken from lakes and ponds in Belgium. Other workers recorded members of genus Naegleria by PCR in rivers in Belgium and Switzerland ${ }^{(34)}$ and Venezuela and Germany ${ }^{\left({ }^{35}\right)}$ in greatly lower percentages than that recorded in the present study, reaching $56.4,27.7,44.4$, and $11.1 \%$, respectively.

In the present investigation, the prevalence of Naegleria by PCR reached $100 \%$ in the 5 culturally positive tap water samples for Naegleria. Other workers in Egypt detected Naegleria amoebae by PCR in a slightly zero percentage $(0 \%)$ in microscopically positive tap water samples ${ }^{(33)}$.

According to the results of the present study, by using the species-specific primers none of the detected samples Naegleria isolates proved belonging to the species $N$. fowleri. This species was reported from Egyptian aquatic habitats ${ }^{(32)}$. As $N$. fowleri is the only species of Naegleria capable of infecting and causing pathology to humans ${ }^{(8)}$, its absence means that there are no hazards associated with the presence of Naegleria isolates in the present study. Absence of $N$. fowleri might be due to the low cultivation temperature $\left(37^{\circ} \mathrm{C}\right)$, or more likely, a true absence, as no clinical case of PAM has been reported in Egypt. The absence of PAM cases in Egypt, whether due to a low prevalence of $N$. fowleri in aquatic environment or a misdiagnosis of PAM cases, necessitates further molecular studies in Egypt using greater sample sizes ${ }^{(\mathbf{3 3})}$.

\section{CONCLUSIONS}

The conventional drinking water treatment system for surface water was better than that of only chlorine disinfection for ground water in removing FLAs. In general, the persistence of FLAs drinking tap water unfortunately exerts public health hazards.

Financial support and sponsorship: Nil.

Conflict of interest: Nil.

\section{REFERENCES}

1. Ali N, Kamel Z, Wahba S (2020): Ultrasonic as Green Chemistry for Bacterial and Algal Control in Drinking Water Treatment Source. Egyptian Journal of Chemistry, 63 (10): 3-6.
2. Mellou K, Katsioulis A, Potamiti-Komi M et al. (2014): A large waterborne gastroenteritis outbreak in central Greece, March 2012: challenges for the investigation and management. Epidemiology \& Infection, 142 (1): 40-50.

3. WHO (2014): Progress on Sanitation and Drinking-Water. Pp: 55. https://apps.who.int/iris/handle/10665/44272

4. Abdul Majid M, Mahboob T, Mong B et al. (2017): Pathogenic waterborne free-living amoebae: An update from selected Southeast Asian countries. PLoS One, 12 (2): 169-175.

5. Panda A, Khalil S, Mirdha B et al. (2015): Prevalence of Naegleria fowleri in Environmental Samples from Northern Part of India. PLoS One, 10 (10): 137-143.

6. Gupta N, Bhaskar H, Duggal S et al. (2009): Primary amoebic meningoencephalitis: first reported case from Rohtak, North India. Braz J Infect Dis., 13 (3): 236-237.

7. Maruyama S, Matsuzaki M, Misawa $\mathrm{K}$ et al. (2009): Cyanobacterial contribution to the genomes of the plastidlacking protists. BMC Evol Biol., 9 (1): 197-203.

8. Parija S, Jayakeerthee S (1999): Naegleria fowleri: afree living amoeba of emerging medical importance. J Commun Dis., 31 (3):153-9.

9. Al-Herrawy A, Khalil M, EL-Sherif S et al. (2017): Surveillance and molecular identification of Acanthamoeba and Naegleria species in two swimming pools in Alexandria University, Egypt. Iran J Parasitol.,12 (2): 196205.

10. Yoder J, Eddy B, Visvesvara G et al. (2010): The epidemiology of primary amoebic meningoencephalitis in the USA, 1962-2008. Epidemiol Infect., 138 (7): 968- 75.

11.HPA (2004): Isolation and identification of Acanthamoeba species. $17: 2 . \quad$ http://www.hpastandardmethods. org.uk/pdf_sops.asp.

12. Andrew D (2018): Standard method for the examination of water and wastewater. American Public Health Association $21^{\text {st }}$ ed., WEF and AWWA, Washington, DC 2011. https://www.worldcat.org/title/standard-methods-for-theexamination-of-water-and-wastewater/ oclc/156744115

13. Özçelik S, Coşkun K, Yünlü Ö et al. (2012): The Prevalence, Isolation and Morphotyping of Potentially Pathogenic Free-Living Amoebae from Tap Water and Environmental Water Sources in Sivas. Türkiye Parazitoloji Dergisi., 36: 198-203.

14.Edagawa A, Kimura A, Kawabuchi-Kurata $T$ et al. (2009): Isolation and genotyping of potentially pathogenic Acanthamoeba and Naegleria species from tap-water sources in Osaka, Japan. Parasitology Research, 105: 110917.

15.Stockman L, Wright $C$, Visvesvara $\mathbf{G}$ et al. (2011): The prevalence of Acanthamoeba spp and other free living amoebae in household water, Ohio, USA 1990-1992. Parasitology Research, 108: 621-7.

16. Hammersmith K (2006): Diagnosis and management of Acanthamoeba Keratitis. Current Opinion in Ophthalmology, 17: 327-31.

17.Garcia A, Goni P, Cieloszyk J et al. (2013): Identification of free-living amoebae and amoeba-associated bacteria from reservoirs and water treatment plants by molecular techniques. Environ Sci Technol., 47: 7: 3132-40.

18. Pelandakis M, Serre S, Pernin $P$ (2000): Analysis of the 5.8S rRNA gene and the internal transcribed spacers in 
Naegleria spp. and in N.fowleri. J Eukaryot Microbiol., 47: 116-21.

19.Smith D (1993): Agarose gel electrophoresis. Methods in molecular biology. In: Murphy D, Carter DA, editors. Transgenesis techniques. Totowa: Humana Press Inc.

20. Kilic A, Tanyuksel J, Sissons D et al. (2004): Isolation of Acanthamoeba isolates belonging to T2, T3, T4, T7 genotypes from environmental samples in Ankara, Turkey. Acta Parasitol., 49: 246-252.

21. Richard R, Ithoi I, Abd Majid M et al. (2016): Monitoring of waterborne parasites in two drinking water treatment plants: a study in Sarawak, Malaysia. International Journal of Environmental Research and Public Health, 13 (7): 641-47.

22.Ghadar-ghadr S, Solhjoo K, Norouz-nejad $M$ et al. (2012): Isolation and identification of free-living amoeba (Naegleria and Acanthamoeba) in Shiraz water resources by morphological criteria. Journal of Jahrom University of Medical Sciences, 10 (3): 26-33.

23.Al-Herrawy A, Marouf $M$, Zahglol $N$ et al. (2019): Detection and removal of free-living amoebae in two different facilities for drinking water by culture and PCR. Egyptian Journal of Aquatic Biology and Fisheries, 23 (4): 627-637.

24. Tsvetkova N, Schild S, Panaiotov D et al. (2004): The identification of free-living isolates of amoebae from Bulgaria. Parasitol. Res., 29: 405-413.

25. Corsaro D, Feroldi V, Saucedo G et al. (2009): Novel chlamydiales strains isolated from a water treatment plant. Environ. Microbiol., 11(1): 188-200.

26. Hamadto H, Aufy S, El-Hayawan I et al. (1993): Study of free living amoebae in Egypt. J Egypt Soc Parasitiol., 23 (3): 631-7.
27.Di Filippo M, Santoro M, Lovreglio $P$ et al. (2015): Isolation and molecular characterization of freeliving Amoebae from different water sources in Italy. Int $\mathbf{J}$ Environ Res Publ Health, 12 (4): 3417-27.

28. Ramirez E, Robles E, Martinez M et al. (2016): Distribution of free-living amoebae in springs in Morelos, Mexico. Global Advanced Research Journal of Microbiology, 5 (6): 57-67.

29.Kao P, Chou M, Tao C et al. (2013): Diversity and seasonal impact of Acanthamoeba species in a subtropical rivershed. Biomed Res Int., 21: 405794.

30. Butkus M, Bays J, Labare M (2003): Influence of surface characteristics on the stability of Cryptosporidium parvum oocysts. Appl Environ Microbiol., 69: 3819-3835.

31. Dupuy M, Berne P, Herbelin P et al. (2014): Sensitivity of free-living amoeba trophozoites and cysts to water disinfectants. J Hyg Environ Health, 217: 335-339.

32.Al-Herrawy A, Gad M (2015): Isolation and molecular identification of Naegleria fowleri from Nile River, Egypt. J Egypt Public Health Assoc., 90 (4): 161-5.

33.El-Badry A, Aufy S, El-Wakil E et al. (2020): First identification of Naegleria species and Vahlkampfia ciguana in Nile water, Cairo, Egypt: Seasonal morphology and phylogenetic analysis. Journal of Microbiology, Immunology and Infection, 53 (2): 259-265.

34. Behets J, Seghi F, Declerck P et al. (2003): Detection of Naegleria spp. and Naegleria fowleri: a comparison of flagellation tests, ELISA and PCR. Water Sci Technol., 47: 117-22.

35.Hoffmann R, Michel R (2001): Distribution of free-living amoebae (FLA) during preparation and supply of drinking water. Int J Hyg Environ Health, 203: 215-219. 